\title{
A simulation model describing the population dynamics and damage poten- tial of the rose grain aphid, Metopolophium dirhodum (Walker) (Hemiptera: Aphididae), in the UK
}

\author{
X. Zhou and N. Carter \\ AFRC Institute of Arable Crops Research, Rothamsted Experiment Station, Harpenden, Herts, \\ AL5 $2 J Q, U K$
}

\section{J. MUMFORD}

Silwood Centre for Pest Management, Imperial College at Silwood Park, Ascot, Berks, SL5 7PY, UK

\begin{abstract}
Metopolophium dirhodum (Walker) is occasionally a pest of cereals in the UK. A simulation model was developed to study its population dynamics and damage potential. The model was initiated by aphid immigration as measured by $12 \cdot 2-\mathrm{m}$ suction trap samples and with temperature as the major driving variable. It was validated with field observations from three contrasting years, 1979,1985 and 1986 . The model accurately predicted aphid populations and yield loss in a major outbreak year (1979) but was less accurate when densities were lower (1985 \& 1986). Possible reasons for these discrepancies are discussed.
\end{abstract}

\section{Introduction}

Cereal aphids are important pests in Western Europe (Rabbinge \& Carter, 1984), with large infestations causing losses in both yield and quality (Lee et al., 1981). Forecasting outbreaks of cereal aphids is an important component in cereal pest management, and several schemes have been developed, mainly for Sitobion avenae (F.) (Rabbinge et al., 1979; Carter, 1985; Wratten et al., 1986). Less attention has been given to the rose grain aphid, Metopolophium dirhodum (Walker), although it too can reach pest status, e.g. in 1979. A simulation model was developed, based on information from the literature, to study its population dynamics and damage potential.

\section{Model structure}

A systems approach was used to list the factors thought to be important to $M$. dirhodum biology, and an interaction matrix was constructed (Holt et al., 1987) (Fig. 1).

\section{Immigration and emigration}

The model simulated population development from the start of the migration by estimating the number of alates landing per shoot per day on cereals using samples from the Rothamsted Insect Survey suction traps $(12.2 \mathrm{~m})$ (Taylor \& Palmer, 1972). The number of $M$. dirhodum landing per shoot $(y)$ was dependent on the numbers of aphids in the daily 


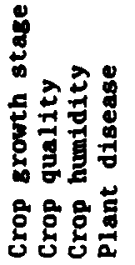

1234

Temperature

Rainfal1

Wind

\section{Variety}

Crop density

Crop srowth stage

Crop quality

Crop humidity

Fertilizer

Pesticides

Sitobion avenae

Other pests

Parasitoids

Predators

Insect disease

Plant disease

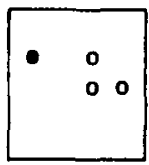

1234

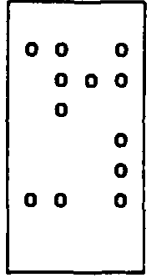

1234

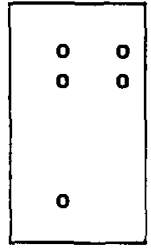

1234

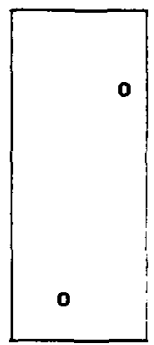

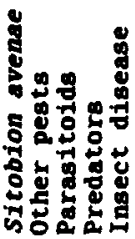

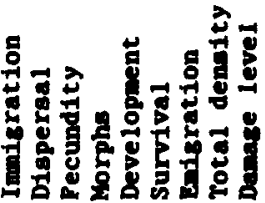

123456789

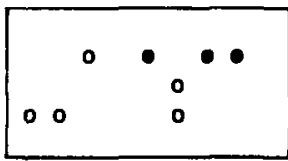

123456789

2345

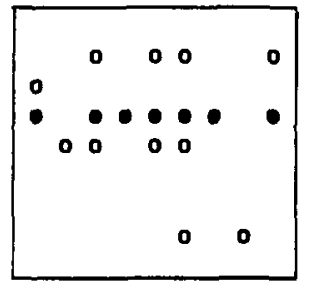

123456789

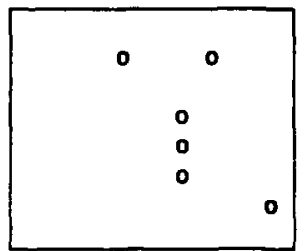

123456789

12345

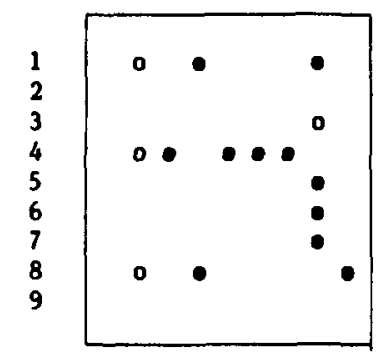

\section{Immigration \\ Dispersal \\ Fecundity \\ Norphs \\ Development \\ Survival \\ Bmigration \\ Total density \\ Damage leve 1}

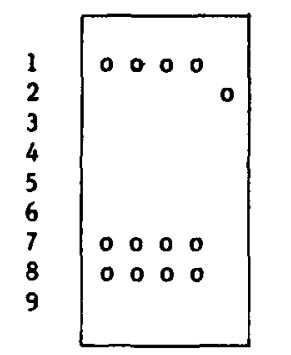

Fig. 1.-Relationships between components in the Metopolophium dirhodum system. (Symbols in cells indicate direct effects of row components on corresponding column components; represents relations between elements incorporated in the model; $\bigcirc$ indicates that relationships or interactions may exist but were not included in the model; blank cells indicate that no relationships were thought to exist between respective elements.) 
suction-trap samples $(s)$, a concentration factor ( $x$, usually equal to 40 (Carter et al., 1982)) and the number of shoots $/ \mathrm{m}^{2}(n)$ :

$$
y=(0.0237 x / n) s
$$

where 0.0237 was calculated based on assumptions of a density:height gradient of -1.0 , which is the regression coefficient of $\log$ density at a certain height $(z)$ on $\log z$, a flight time of two hours and random deposition such that each aphid in the trap corresponds to 237 aphids/ha (from Taylor \& Palmer, 1972).

Suction-trap samples early in the season were assumed to consist entirely of immigrants, but later, as the cereals ripened, emigrants predominated. The proportion of immigrants $(I)$ in suction-trap samples $\left(I_{\mathrm{c}}\right)$ was dependent on the current crop growth stage $\left(S_{\mathrm{c}}\right)$, the crop growth stage when emigrants first appeared $\left(C_{1}=\right.$ G.S. 77 (Zadoks et al., 1974)) and the crop growth stage when all alates were emigrants $\left(C_{2}=\right.$ G.S. 82$)$ :

$$
I=I_{\mathrm{c}}\left(1-\frac{S_{\mathrm{c}}-C_{1}}{C_{2}-C_{1}}\right)
$$

Alates developing on the crops were assumed to emigrate immediately after moulting to the adult stage.

\section{Development and survival}

Plotting development rate (1/development time $\left(d_{1}\right.$ or $\left.\left.d_{2}\right)\right)$ against temperature $(t)$, using the data of Dean (1974), revealed two lines (Fig. 2, Equations 3 \& 4) with the break at $20^{\circ} \mathrm{C}$ :

$$
\begin{aligned}
& d_{1}=10^{-3}(0 \cdot 522+0 \cdot 24 t) \quad\left(t \leq 20^{\circ} \mathrm{C}\right) \\
& d_{2}=10^{-3}(8.912-0.198 t) \quad\left(t>20^{\circ} \mathrm{C}\right)
\end{aligned}
$$

A low development threshold of $-2 \cdot 2^{\circ} \mathrm{C}$ was determined when the development rate $\left(d_{1}\right)$ was equal to zero in Equation 3.

Daily maximum $\left(y_{1}\right)$ and minimum $\left(y_{2}\right)$ temperatures, which were assumed to occur at $14.00 \mathrm{~h}$ and sunrise, respectively, were used to calculate hourly temperatures $\left(t_{\mathrm{h}}\right)$ :

$$
t_{\mathrm{h}}=\left(y_{1}-y_{2}\right) \sin (\alpha+\beta h) / 2+\left(y_{1}+y_{2}\right) / 2
$$

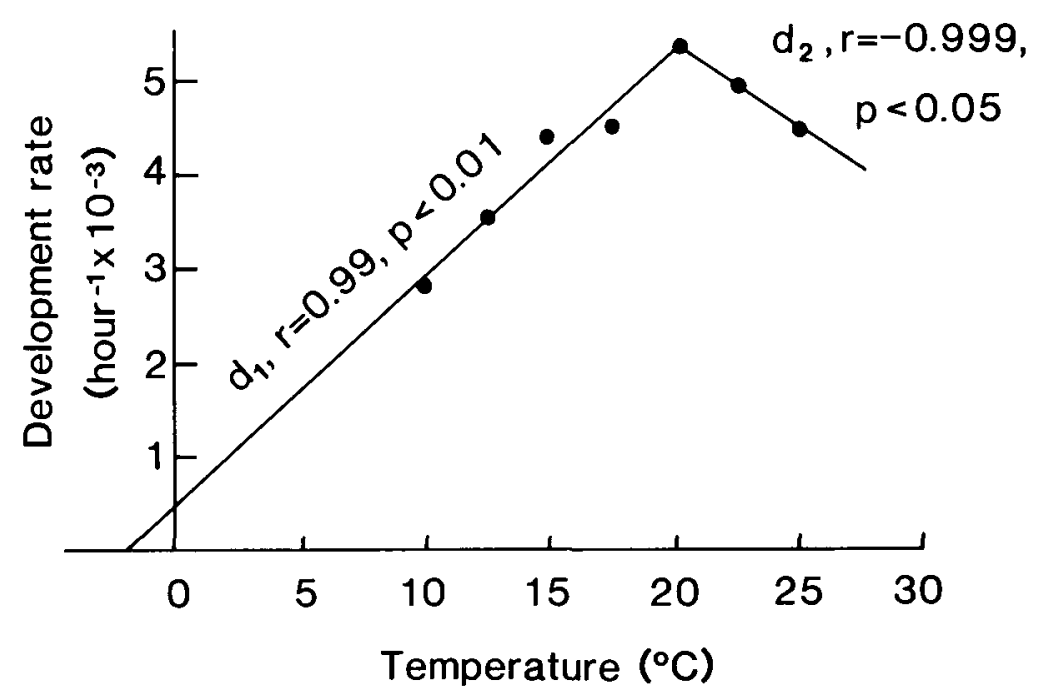

Fig. 2.-The relationship between development rate of Metopolophium dirhodum and temperature (after Dean, 1974). 
where $h$ is the successive hourly time throughout each day and $\alpha$ and $\beta$ are constants determined by the time of sunrise.

Physiological time $(p)$ was calculated using Equation 6 when the temperature $\left(t_{\mathrm{h}}\right)$ was less than or equal to $20^{\circ} \mathrm{C}$ and Equation 7 when the temperature was greater than $20^{\circ} \mathrm{C}$ :

$$
\begin{aligned}
& p=t_{\mathrm{h}}+2 \cdot 2 \\
& p=d_{1}^{-1}\left\{d_{2}\left(t_{\mathrm{h}}\right)\right\}+2 \cdot 2
\end{aligned}
$$

The development times of each nymphal instar and adult apterae (Dean, 1974) were calculated in hour-degrees above the development threshold of $-2 \cdot 2^{\circ} \mathrm{C}$. The length of the alatiform fourth-instar nymphs was assumed to be 1.5 times that of the apteriform fourthinstar nymphs (Carter et al., 1982). The lifespans of alate and apterous adults were dependent on crop growth stages based on the following assumptions: the values for development lifespans on seedlings (Dean, 1974) were used for the development time before the end of inflorescence (G.S. 59), when the crop growth stage was between the end of inflorescence and early milk (G.S. 73) apterous adults lived 0.2 times longer than that before the end of inflorescence, and, for crop growth stages greater than early milk, the adult lifespan was half that before the end of inflorescence. Alate adult lifespan was kept constant at half the apterous adult lifespan before the end of inflorescence.

Nymphal and adult survival rates of the apteriform morph were dependent on crop growth stage: 0.87 and 0.89 before early milk (G.S. 73) and 0.23 and 0.54 afterwards, respectively (Watt, 1979). The survival rates of the alatiform morph were assumed to be the same as those of the apterous morph.

\section{Reproduction and morph determination}

Reproduction rates were dependent on temperature, morph (alate or apterous) and crop growth stage. The rate per apterous adult per hour-degree was calculated from Dean (1974) and was the mean of the values at four temperatures $\left(10,15,20\right.$ and $\left.25^{\circ} \mathrm{C}\right)$. This value was reduced by 0.67 for crop growth stages before the end of inflorescence (G.S. 59) and increased by 1.2 for crop growth stages between the end of inflorescence (G.S. 59) and early milk (G.S. 73) (Thornback, 1981). The reproduction rate was assumed to be zero for crop growth stages after early dough (G.S. 83). Alate reproductive rates were those of apterous adults multiplied by 0.785 (Wratten, 1977).

The eventual morph of a nymph was dependent on aphid density $(d)$ and crop growth stage $(g)$ (Carter, 1985):

$$
p_{\mathrm{r}}=-27 \cdot 189+2 \cdot 603 d+0 \cdot 847 g
$$

where $p_{\mathrm{r}}$ is the proportion of newly born alatiform nymphs.

\section{Crop growth model}

The decimal code (Zadoks et al., 1974) was used to simulate winter wheat growth, using a polynomial equation between crop growth stage $\left(C_{c}\right)$ and accumulated physiological time (tot) above a development threshold of $6^{\circ} \mathrm{C}$ (Carter, 1985):

$$
C_{\mathrm{c}}=26 \cdot 336+0 \cdot 173 \text { tot }-0.000125 \text { tot }^{2}
$$

\section{Crop yield loss}

The daily rate of yield loss $\left(R_{\mathrm{i}}\right)$ caused by $M$. dirhodum per aphid unit (one aphid unit is equivalent to three first- to third-instar nymphs, one fourth instar nymph or one alate or apterous adult) varied with crop growth stage (Wratten et al., 1979, Lee et al., 1981, Holt et al., 1984). When the crop development was before the start of booting (G.S. 40), it was assumed that aphid infestations did not cause yield loss as the crop was able to compensate. The damage rates, as proportions of potential yield when uninfested, for other periods during the crop development was calculated from the literature (Table I). The rate was assumed to be zero after the early dough stage (G.S. 83). 
TABLE I. Yield loss as a proportion of the potential yield per aphid unit day

\begin{tabular}{|c|c|c|}
\hline Crop stage & $\begin{array}{l}\text { Proportional } \\
\text { yield loss }\end{array}$ & $\begin{array}{l}\text { References } \\
\text { or } \\
\text { assumption }\end{array}$ \\
\hline $\begin{array}{l}<\text { G.S. } 40 \\
\text { G.S. } \geq 40-<55 \\
\text { G.S. } \geq 55-<60 \\
\text { G.S. } \geq 60-<70 \\
\text { G.S. } \geq 70-<77 \\
\text { G.S. } \geq 77-<83 \\
\geq \text { G.S. } 83\end{array}$ & $\begin{array}{l}0.0 \\
1.556 \times 10^{-4} \\
3.765 \times 10^{-4} \\
4.87 \times 10^{-4} \\
3.83 \times 10^{-4} \\
1.92 \times 10^{-4} \\
0.0\end{array}$ & $\begin{array}{l}\text { Assumption } \\
\text { Holt et al. }(1984) \\
\text { Wratten et al. }(1979) \\
\text { Lee et al. }(1981) \\
\text { Holt et al. }(1984) \\
\text { Assumption }\end{array}$ \\
\hline
\end{tabular}

Estimated daily yield loss $\left(L_{\mathrm{i}}\right)$ was dependent on the daily aphid index $\left(A_{\mathrm{i}}\right.$, the sum of the numbers of aphid units) present on plants:

$$
L_{\mathrm{i}}=A_{\mathrm{i}} R_{\mathrm{i}}
$$

and then accumulated to give a total yield loss $\left(T_{\mathrm{i}}\right)$ :

$$
T_{\mathrm{i}}=\Sigma A_{\mathrm{i}} R_{\mathrm{i}}
$$

\section{Field data for validation}

The model was validated using data from field trials at Rothamsted, southern England, in 1979,1985 and 1986 .

In 1979, four counts of aphid densities made of the total, nymphal stage, and alate and apterous adult populations during the summer were from a multidisciplinary field experiment (Prew et al., 1983). They were from plots not receiving summer aphicide and separated into early and late sowing treatments and were used in the validation of the model.

In 1985 and 1986, the total aphid densities sampled at approximately weekly intervals in the field were from eight and 12 unsprayed plots, respectively, in experiments to study insecticide persistence on aphids (Carter et al., in press).

Aphid migration data were from the $12 \cdot 2-\mathrm{m}$ suction trap and maximum and minimum temperatures from the meteorological station, both at Rothamsted.

The model was started on the day the first $M$. dirhodum was sampled in the suction trap. The corresponding initial crop growth stages were G.S. 31 in 1979, 35 in 1985 and 68 in 1986. The number of shoots per square metre was set at 500 each year.

\section{Results}

In 1979, the model predicted accurately the size of the observed maximum aphid density and the timing of its occurrence ( 109 aphids/shoot on 24 July). The model also predicted accurately the exponential increase of $M$. dirhodum after 25 June (Fig. $3 A \& B$ ). Early in the season, the model slightly overestimated the field populations in both the early and late sown plots, but the predictions were more accurate later in the season.

In 1985, the predicted population was larger and occurred seven days later than the observed peak. The observed aphid population increased steadily until 15 July and then declined rapidly. The model overestimated the population starting on 24 June and carried on increasing until 22 July to reach a peak of $59 \cdot 9$ aphids/shoot (Fig. $3 C$ ).

In 1986, the model again overestimated the peak density but was only three days late in predicting its timing (6.3/shoot on 17 July). It was late estimating the initial build-up (Fig. $3 D)$.

The simulation results from the total population were separated into three components: total nymphs, and alate and apterous adults in 1979 (Fig. 4). The model accurately predicted the total numbers of nymphs and apterous adults (Fig. $4 A \& C$ ) but underestimated the observed peak of alates (Fig. $4 B$ ).

The model predicted a final yield loss of $11.5 \%$ compared with the observed yield loss of $12.7 \%$ in 1979 (Prew et al., 1983) and also accurately predicted an average yield loss of $5.5 \%$ while the yield loss was $4.7 \%$ in the experimental plots in 1985 . The estimated and field yield losses were both near zero in 1986 . 


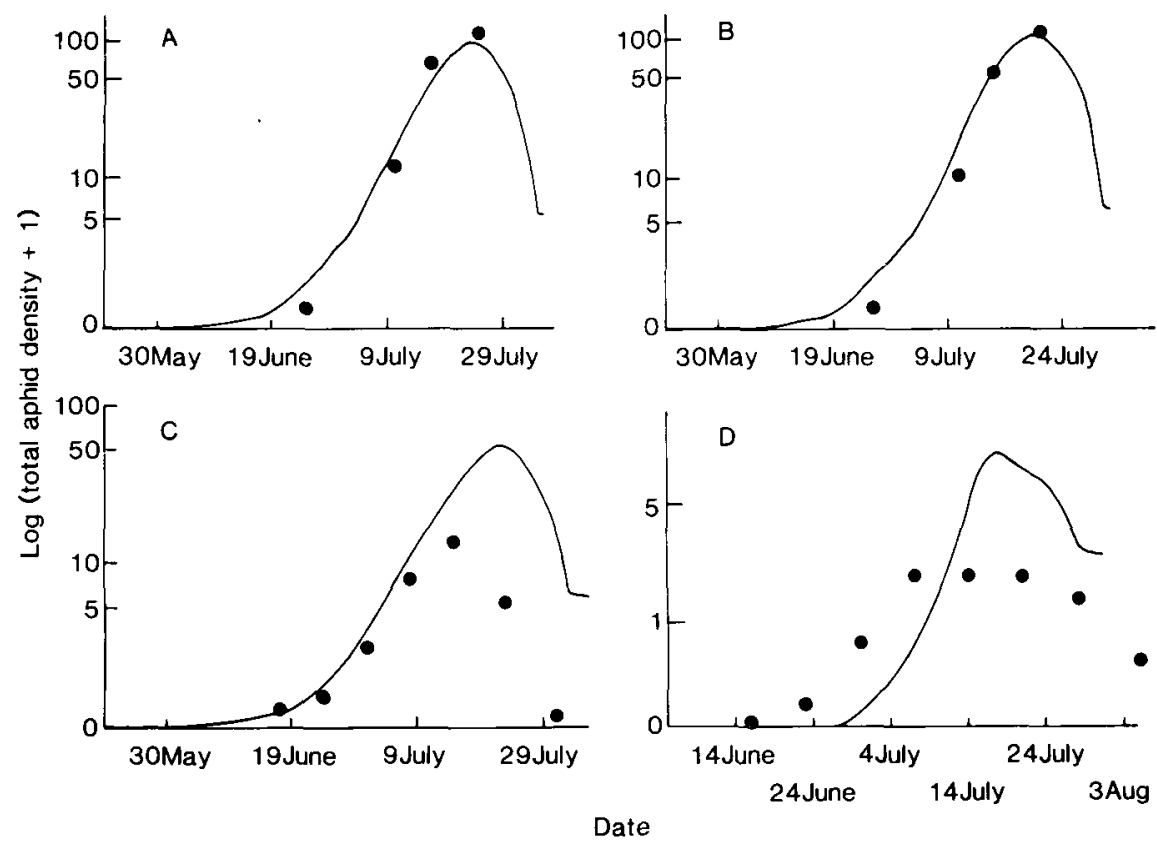

Fig. 3.-Comparison of predicted (-) and observed (O) total densities of Metopolophium dirhodum in (A) early and (B) late sown plots in 1979, (C) 1985 and (D) 1986.
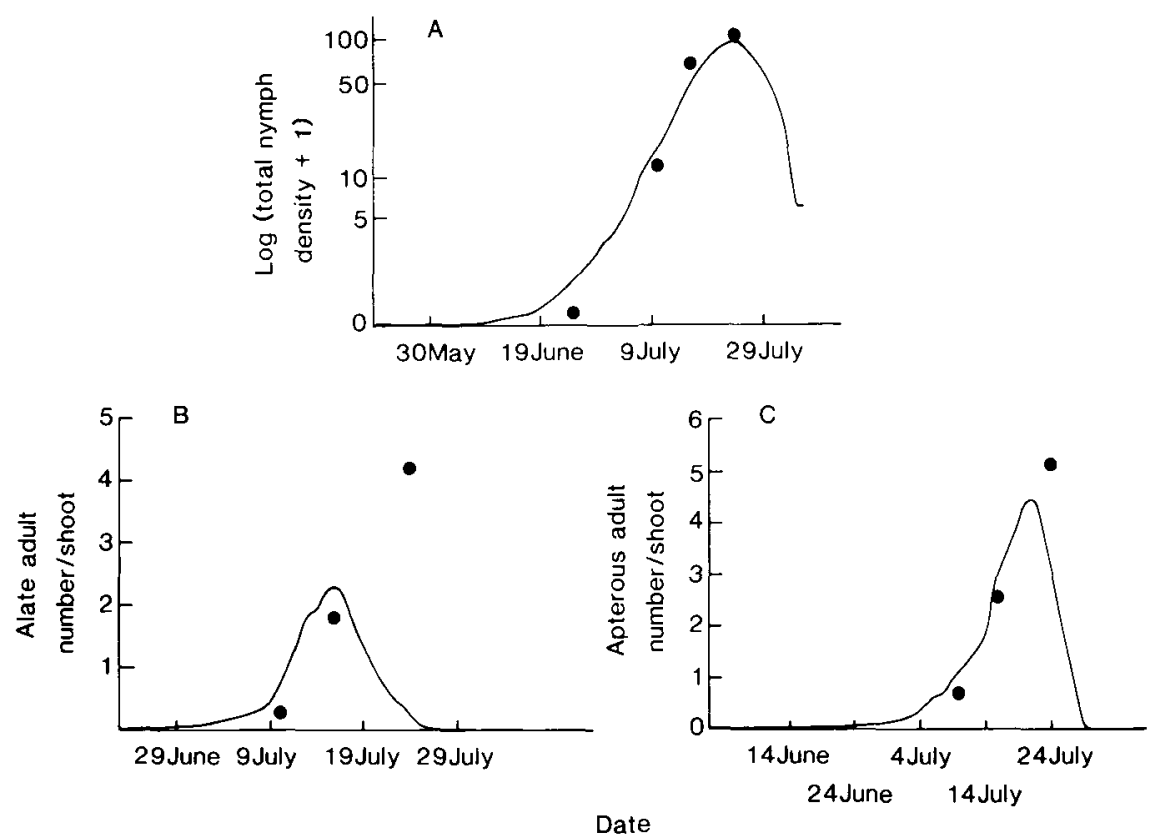

Fig. 4.-Comparison of predicted $(-)$ and observed $(\square)$ densities of $(A)$ nymphs, $(B)$ alate adults and $(C)$ apterous adults of Metopolophium dirhodum from early sown plots in 1979. 


\section{Discussion}

In 1979, there were few immigrants and small field populations in spring, but the warm dry weather in July and delayed crop development due to cold weather in the previous winter allowed these populations to increase rapidly to very high levels in the absence of significant effects of natural enemies (Dewar et al., 1980). The model predicted accurately this exponentional increase. In contrast, in 1985, cool and wet weather in June prevented rapid aphid increase early in the season and when the aphid population did start to increase, the cereals had developed beyond the more susceptible stages (Tatchell et al., 1986). Therefore, the aphid populations remained small and were well below the levels of infestation predicted by the model (Fig. $3 C$ ). In 1986, the first $M$. dirhodum was caught at the end of June at Rothamsted and natural enemies may have had a significant effect on reducing aphid population development (Carter, 1987). The model only included a low background mortality so these effects of natural enemies could explain the gradual divergence of predictions from the model with the observed densities and also the earlier decrease in the observed population (Fig. $3 C \& D$ ).

The numbers of immigrant aphids were obtained from daily suction-trap samples, and these may be less reliable at low densities than at high ones. For example, aphids occurred in the field about ten days before the first $M$. dirhodum was caught in the suction trap in 1986. Also, the proportions of the suction-trap samples during the season, which were assumed to be immigrants based on the Equation 2 in the model, may not accurately reflect the proportions in the population sampled.

The predicted yield losses were similar to those in the field in the three years, although the predicted yield loss was slightly higher in 1985 . However, the observed yield losses were obtained from the differences between control plots and plots sprayed with insecticide. The yield in the latter would still be lower due to the presence of the reduced aphid populations so that the actual yield losses would have been slightly higher than the observed results.

\section{Acknowledgement}

The work is supported by the British Council and the Chinese Government.

\section{References}

CARTER, N. (1985). Simulation modelling of the population dynamics of cereal aphids.-Biosystems 18, 111-119.

CARTER, N. (1987). Cereal aphids in summer.-Rep. Rothamsted exp. Stn 1986 (1), 86.

CARTer, N., Dixon, A. F. G. \& Rabilnge, R. (1982). Cereal aphid populations: biology, simulation and prediction.-91 pp. Wageningen, Pudoc.

Carter, N., Powell, W., Wright, A. F. \& Ashby, J. E. (in press). The effectiveness of different insecticides applied at various growth stages to control aphids on winter wheat.-Crop Prot.

DEAN, G. J. (1974). Effect of temperature on the cereal aphids Metopolophium dirhodum (Wlk.), Rhopalosiphum padi (L.) and Macrosiphum avenae (F.) (Hem., Aphididae).-Bull. ent. Res. 63, 401-409.

Dewar, A. M., Woiwod, I. \& De JANvry, E. C. (1980). Aerial migrations of the rose-grain aphid, Metopolophium dirhodum (Wlk.), over Europe in 1979._Pl. Path. 29, 101-109.

Holt, J., Cook, A. G., Perfect, T. J. \& Norton, G. A. (1987). Simulation analysis of brown planthopper (Nilaparvata lugens) population dynamics on rice in the Philippines.-J. appl. Ecol. 24, 87-102.

Holt, J., Griffiths, E. \& Wratten, S. D. (1984). The influence of wheat growth stage on yield reductions caused by the rose-grain aphid, Metopolophium dirhodum.-Ann. appl. Biol. 105, $7-14$.

Lee, G., Stevens, D. J., Stokes, S. \& Wratten, S. D. (1981). Duration of cereal aphid populations and the effects on wheat yield and breadmaking quality.-Ann. appl. Biol. 98, 169-178.

Prew, R. D., Church, B. M., Dewar, A. M., Lacey, J., Penny, A., Plumb, R. T., Thorne, G. N., TodD, A. D. \& Williams, T. D. (1983). Effects of eight factors on the growth and nutrient uptake of winter wheat and on the incidence of pests and diseases.-J. agric. Sci. 100, 363382.

Rabbinge, R., Ankersmit, G. W. \& Pak, G. A. (1979). Epidemiology and simulation of population development of Sitobion avenae in winter wheat.-Neth. J. Pl. Path. 85, 197-220. 
Rabinge, R. \& CARTer, N. (1984). Aphids in Netherlands. A subsystem of EPIPRE.-pp. 242-253 in Conway, G. R. (Ed.). Pest and pathogen control. Strategic, tactical and policy models.488 pp. Chichester, Wiley.

Tatchell, G. M., Carter, N., Worwod, I. P., Dupuch, M. J., French, V. M., Mitchell, C. S., Parker, S. J., TAylor, M. S. \& Riley, D. K. (1986). Aphid studies, surveying.-Rep. Rothamsted exp. Stn 1985 (1), 93-94.

TAylor, L. R. \& Palmer, J. M. P. (1972). Aerial sampling.-pp. 189-234 in Van Emden, H. F. (Ed.). Aphid technology.-344 pp. London, Academic Press.

Thornback, N. (1981). Factors determining the abundance of Metopolophium dirhodum.--Ph.D. thesis, Univ. East Anglia.

WATT, A. D. (1979). The effect of cereal growth stages on the reproductive activity of Sitobion avenae and Metopolophium dirhodum.-Ann. appl. Biol. 91, 147-157.

Wratten, S. D. (1977). Reproductive strategy of winged and wingless morphs of the aphids Sitobion avenae and Metopolophium dirhodum.-Ann. appl. Biol. 85, 319-331.

Wratten, S. D., Lee, G. \& Stevens, D. J. (1979). Duration of cereal aphid populations and the effects on wheat yield and quality.--pp. 1-8 in Proceedings of the 1979 British Crop Protection Conference-Pest and Diseases (10th British Insecticide and Fungicide Conference) 19th to 22nd November 1979. Hotel Metropole, Brighton, England. Vol. 1.-pp. 1-302. Croydon, Surrey, UK, Br. Crop Prot. Coun.

Wratten, S. D., MANN, B. \& Wood, D. (1986). Information exchange in future crop protectioninteractions within the independent sector: Prestel Farmlink.-pp. 703-711 in 1986 British Crop Protection Conference. Pests and Diseases. Proceedings of a conference held at Brighton Metropole, England, November 17-20 1986. Vol. 2.-pp. 401-885. Thornton Heath, UK, Br. Crop Prot. Coun.

Zadoks, J. C., Chang, T. T. \& Konzak, C. F. (1974). A decimal code for the growth stages of cereals.-Weed Res. 14, 415-421.

(Received 25 October 1988)

(C) C.A.B International, 1989 